\title{
Mapping Hotel Brand Positioning and Competitive Landscapes by Text-mining User- generated Content
}

\begin{abstract}
This study uncovers hotel brand positioning and competitive landscape mapping by text-mining user-generated content (UGC). Rather than relying on a single dimension of consumer evaluation, the current study detects brand attributes by using both customer preferences as well as perceptual performance to develop meaningful insights. For this, the study combines content analysis and repertory grid analysis (RGA) to answer three key research issues. 111,986 hotel reviews from two biggest Chinese cities are used to explore and visualize the competitive landscape of six selected hotel brands across three hotel categories. Findings from the study will not only advance the existing literature on brand positioning and competitive landscape mapping but also help practitioners in developing brand positioning strategies to fight competitors within and across hotel categories.
\end{abstract}

Keywords: Brand Positioning; Competitive landscape; Repertory Grid Analysis; Text mining; User-generated content

\section{Highlights:}

- Integrating content analysis and RGA to uncover hotel brand positioning and competitive landscaping.

- The evaluations on detected attributes involve both customer preferences (importance) as well as perceptual performance.

- The study helps practitioners by measuring brand preference, mapping strategic competitive landscape and improving competitive perforamnce.

- Assymetric competitive relationships between selected brands are identified

\section{Introduction}

In the hospitality industry, building a strong hotel brand positioning requires more than just associating a property with a name and a logo or creating a marketing campaign (Cai and Hobson, 2004). In order to create a unique and differentiated hotel brand positioning, marketer need to develop a strategy that not only relates to the needs of the consumers (Choi and Chu, 2001; Oh and Parks, 1997) but also differentiate the property and value proposition meaningfully from other competing hotels in the same market (Park et al., 1986). A hotel can create unique positioning based on a set of differentiated attributes, targeting a specific user group/s or for a specific usage category (Brown and Ragsdale, 2002; Lewis, 1985). In any case, a unique brand positioning will result into not only higher occupancy, repeat visit and service 
patronage, but also increased profitability and relative resiliency during down industry cycle. Thus, it is perennially important for a marketer to understand how to uniquely position a specific hotel brand by deploying a judicious mix of most appropriate resources and communicating message that resonate to a specific consumer segment (Brown and Ragsdale, 2002; Dev et al., 1995; Park et al., 1986). An additional critical issue facing hotel looking for a strong brand positioning is to distant itself from other competitors by offering and communicating unique tangible and intangible benefits that are difficult for a competitors to copy (Anderson et al., 1999).

To this effect, it is necessary to examine the hotel brand positioning from consumers' perspective and examine the performance of various competing hotels in a market so as to achieve a clear positioning with strong market orientation (Plumeyer et al., 2017). Previous literature in hospitality industry commonly explored hotel brand positioning and competitive landscape issues by either using survey data (e.g., Brown and Ragsdale, 2002; Dev et al., 1995) limiting the insights to pre-specified questions or mining UGC with reliance on a single dimension of consumer evaluations (e.g., Chiu et al., 2015; Krawczyk and Xiang, 2016). The conventional survey-based techniques are characterized by an inherently high dependence on relatively small samples with information selectivity bias and thus believed relatively weak in reflecting holistic customer experience (Krawczyk and Xiang, 2016; Lau et al., 2005). On other hand, recent studies employing large size UGC largely limited the inquiry to a unidimensional evaluation of consumer opinion on detected brand attributes on importance (e.g., Krawczyk and Xiang, 2016) or perceptual performance (Chiu et al., 2015) offering implications that are lopsided with limited practical usability in brand positioning/repositioning decisions (Keller, 1993; Lewis, 1985). According to the Expectancy Confirmation Theory (ECT) introduced by Oliver (1980), customer evaluation is the result of comprehensive comparison between customer expectation and perception and both of them should be used to understand overall brand positioning. Therefore, the present study attempts to map hotel brand positioning and competitive landscape by detecting brand attributes using both customer preferences as well as perceptions to develop empirically robust and practically more meaningful insights.

Overall, brand positioning and developing competitive strategy involve reflecting on a series of critical issues, such as: a) what are the key customer preferences and/or expectations from the brand? b) who are the key competitors and competitive groups? c) what are the major dimensions on which the brand is competing with key competitors? d) In comparison to key competitors, whether the brand offers better or worse service on selected dimensions? and e) 
how to improve performance of our brand in competitive environment? However, previous empirical studies measuring hotel brand positioning commonly uncover only a part of them and offer limited strategic implications.

Lewis (1985) introduced a two-step approach of analysis to explore positioning issues in the hospitality industry, i.e. detecting perceptual difference among competing brands and examine performance of a brand according to customer needs. Based on Lewis' (1981, 1985, 1990) conceptual reflections of hotel positioning, we derive three underlying research issues to map hotel brand positioning and competitive landscape by using UGC, a) detecting brand performance, b) mapping competitive landscape and c) developing competitive strategies. From customer perspective, brand performance deals with the key consumer preferences and expectations from a brand under consideration and whether the brand is able to satisfactorily meet the consumer needs. Competitive landscape mapping attempts to identify the main competing brands in the market and underlying competitive condition measured by key dimensions and/or attributes that define the competition. Lastly, for the purpose of developing competitive strategy, we need to look at the performance of a brand in relation to key competitive factors vis-à-vis main competitors and how to improve the performance of the brand in a competitive environment.

In this study, based on mining big size UGC data of selected hotel chains based in China, we have integrated content analysis and RGA to uncover hotel brand positioning and competitive performance improvement. The evaluation of detected brand attributes involve both customer preferences and perceptual performance uniquely in our research. The former indicates the importance of brand attributes that are used to identify key competitive groups and dimensions, while the latter implies the performance of brand attributes to uncover the competitive strategy for detected competitive groups.

The remainder of the paper is organized as follows. The next section reviews previous studies mapping perceptual brand positioning in competitive environment and introducing the repertory grid technique for brand landscape exploration. The methodology section presents our research design and describes the process of text analytics as well as repertory grid analysis. Thereafter, we discuss our empirical findings in section 4. Finally, we conclude with implications and contributions for both theory and practice. 


\section{Literature Review}

\subsection{Mapping perceptual hotel brand positioning in competitive environment}

Market positioning refers to how the brand is located in the mind of consumers relative to its main competitors (Trout and Ries, 1972). A hotel aspiring to achieve unique positioning should clearly distinguish itself from competitors on the attributes that are most relevant to its target market reflected by differentiated services, price, amenities or customer communication (Brown and Ragsdale, 2002; Torres and Kline, 2006). To this end, the positioning exercise produce additional value if the performance of a hotel can be scaled against other competitors to identify major gaps that hotelier should immediately address (Kozak, 2004, 2002). In order to develop market positioning or re-positioning strategy, previous efforts generally maps competitive landscape by examining customers' opinions about selected attributes in reference to pre-identified brands. Table 1 lists some representative hospitality literature mapping perceptual brand landscape in competitive environment. 


\begin{tabular}{|c|c|c|c|c|c|c|c|c|c|c|c|c|}
\hline \multirow[t]{2}{*}{ Author and Year } & \multicolumn{6}{|c|}{$\begin{array}{l}\text { Method applied for mapping } \\
\text { competitive landscape }\end{array}$} & \multicolumn{2}{|c|}{$\begin{array}{l}\text { Data } \\
\text { Source }\end{array}$} & \multicolumn{2}{|c|}{$\begin{array}{l}\text { Brand } \\
\text { attributes }\end{array}$} & \multicolumn{2}{|c|}{$\begin{array}{l}\text { Customer } \\
\text { opinions }\end{array}$} \\
\hline & 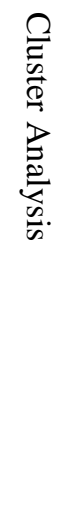 & 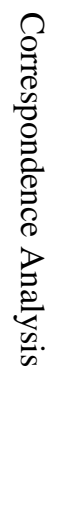 & 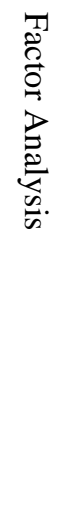 & 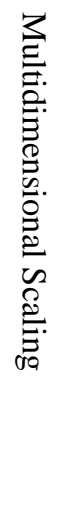 & 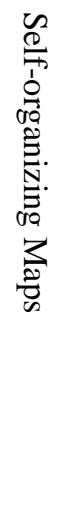 & 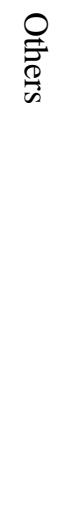 & 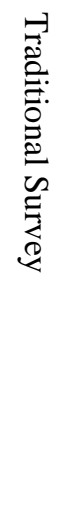 & 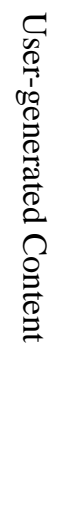 & 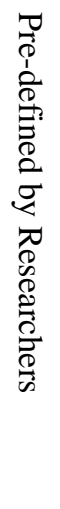 & 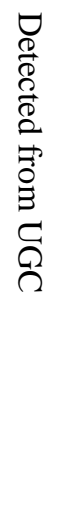 & 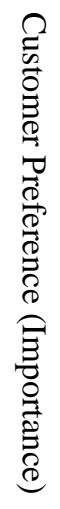 & 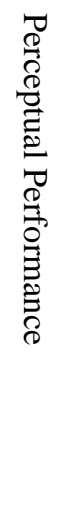 \\
\hline Lewis (1985) & $\sqrt{ }$ & & & & & $\sqrt{ }$ & $\sqrt{ }$ & & $\sqrt{ }$ & & $\sqrt{ }$ & $\sqrt{ }$ \\
\hline Calantone et al. (1989) & & $\sqrt{ }$ & & & & & $\sqrt{ }$ & & $\sqrt{ }$ & & & $\sqrt{ }$ \\
\hline Dev et al. (1995) & & & & $\sqrt{ }$ & & & $\sqrt{ }$ & & $\sqrt{ }$ & & $\sqrt{ }$ & \\
\hline Mazanec (1995) & & & $\sqrt{ }$ & & $\sqrt{ }$ & & $\sqrt{ }$ & & $\sqrt{ }$ & & $\sqrt{ }$ & \\
\hline Kim (1996) & & & $\sqrt{ }$ & $\sqrt{ }$ & & & $\sqrt{ }$ & & $\sqrt{ }$ & & $\sqrt{ }$ & \\
\hline Kim (1998) & & $\sqrt{ }$ & $\sqrt{ }$ & $\sqrt{ }$ & & & $\sqrt{ }$ & & $\sqrt{ }$ & & $\sqrt{ }$ & \\
\hline Prasad and Dev (2000) & & & & & & $\sqrt{ }$ & $\sqrt{ }$ & & $\sqrt{ }$ & & & $\sqrt{ }$ \\
\hline Curry et al. (2001) & $\sqrt{ }$ & & & & $\sqrt{ }$ & & $\sqrt{ }$ & & $\sqrt{ }$ & & & $\sqrt{ }$ \\
\hline Brown and Ragsdale (2002) & & & & & & $\sqrt{ }$ & $\sqrt{ }$ & & $\sqrt{ }$ & & & $\sqrt{ }$ \\
\hline Chen and Uysal (2002) & & $\sqrt{ }$ & & & & & $\sqrt{ }$ & & $\sqrt{ }$ & & $\sqrt{ }$ & \\
\hline Kim and Agrusa (2005) & & $\sqrt{ }$ & & $\sqrt{ }$ & & & $\sqrt{ }$ & & $\sqrt{ }$ & & $\sqrt{ }$ & \\
\hline Kim et al. (2005a) & & $\sqrt{ }$ & & & & & $\sqrt{ }$ & & $\sqrt{ }$ & & $\sqrt{ }$ & \\
\hline Kim et al. (2005b) & & & & $\sqrt{ }$ & & & $\sqrt{ }$ & & $\sqrt{ }$ & & $\sqrt{ }$ & \\
\hline Kim et al. (2007) & & & $\sqrt{ }$ & $\sqrt{ }$ & & & $\sqrt{ }$ & & $\sqrt{ }$ & & & $\sqrt{ }$ \\
\hline Opoku (2009) & & $\sqrt{ }$ & & & & & & $\sqrt{ }$ & & $\sqrt{ }$ & $\sqrt{ }$ & \\
\hline Crotts et al. (2009) & & & $\sqrt{ }$ & & & & & $\sqrt{ }$ & & $\sqrt{ }$ & $\sqrt{ }$ & \\
\hline Wen and Yeh (2010) & & $\sqrt{ }$ & $\sqrt{ }$ & $\sqrt{ }$ & & & $\sqrt{ }$ & & $\sqrt{ }$ & & & $\sqrt{ }$ \\
\hline Chiu et al. (2015) & & $\sqrt{ }$ & & & & & & $\sqrt{ }$ & $\sqrt{ }$ & & & $\sqrt{ }$ \\
\hline Hananto (2015) & & $\sqrt{ }$ & & & & & & $\sqrt{ }$ & & $\sqrt{ }$ & $\sqrt{ }$ & \\
\hline Krawczyk and Xiang (2016) & & $\sqrt{ }$ & & & & & & $\sqrt{ }$ & & $\sqrt{ }$ & $\sqrt{ }$ & \\
\hline
\end{tabular}

Table 1. Hospitality literature investigating brand landscape in competitive environment

Looking at different methods applied to investigate hotel brand landscape in competitive environment, dimensionality reduction analysis (Mazanec, 1995) appears to be one of the widely employed techniques to evaluate how various brands relate to certain attributes in the mind of consumers. For this, multi-dimensional information of brands and their associated attributes are usually condensed into a low-dimensional spatial representation. For instance, Chen and Uysal (2002) used 2-dimensional correspondence analysis to explore and map customers' perceptual view and competitive set of selected US states on twenty six destination attributes. Dev et al. (1995) used multidimensional scaling (2-dimensional) to explore and present perceptual view and competitive set of ten different hotels on seven pre-selected hotel attributes. In order to develop more nuanced and empirically validated insights, hybrid 
dimensionality reduction methods are often employed by previous studies to map brand landscape in a competitive environment. For instance, attribute importance for brand is subjected to a factor analysis for use in further perceptual multidimensional scaling (Kim et al., 2007; Kim, 1998, 1996).

The early literature mainly used small-size survey data to explore customer evaluation on pre-defined brand attributes (e.g. Calantone et al., 1989; Kim, 1998), while later studies commonly explore customer experience on detected attributes based on text-mining huge-size UGC (e.g. Chiu et al., 2015; Krawczyk and Xiang, 2016). In comparison with survey data, scholars argued that UGC is considered open-ended, more objective, cost-effective and unbiased (Chiu et al., 2015; Crotts et al., 2009; Krawczyk and Xiang, 2016; Yamanishi and Li, 2002). Concerning data sources used in previous studies, online sources of UGC are beginning to replace survey-based market research techniques (Kozinets, 2002) as opinion of entire population from selected online platform provides empirically enriched scientific insights (Chang et al., 2014).

Although existing studies investigating brand landscape mapping in the hospitality industry have contributed significantly from both methodological as well as practical perspective, most of these studies provide limited one dimensional evaluation of customer experience. Robets and Lilien (1993) stated that customer's evaluations on a brand involve both perceptions and preferences. Perceptual brand image stems from a comprehensive comparison between brand preference and performance in terms of related attributes (Lewis, 1985; Oliver, 1980). The importance of attributes is used in previous studies to differentiate brands from each other, i.e. who are the key competitors and what are the main competing dimensions, while the performance of attributes is employed to develop competitive strategies (Lewis, 1985), i.e. how to improve brand performance in a competitive environment. However, most of the previous studies uncovered brand positioning based on limited one-dimensional investigation of customer experience by using either perceptual importance or performance (See last two columns in Table 1). Here, some of the studies examined customers' opinions on detected attributes by evaluating the importance of brand associations (e.g. Hananto, 2015; Krawczyk and Xiang, 2016), while others investigated perceptual brand performance based on selected attributes (e.g. Brown and Ragsdale, 2002; Chiu et al., 2015). We argue that using single-side investigation could be misleading and may provide only a limited understanding of brand landscape in competitive environment. Thus, there exist a gap in literature for mapping brand positioning and competitive landscape by jointly using both performance as well as preference. 
Within this context, this study expands Lewis' (1985) work by using customer evaluations on both expectations and perceptions based on text-mining UGC. The study contributes at three levels: 1) detecting customer brand preferences and key expectations based on the frequency of mentioned associations towards brands in UGC, 2) uncovering competitive landscape based on the difference and similarity of mentioned associations among brands in UGC, and 3) developing competitive strategies by measuring the performance on detected brand attributes in reference to competitive groups.

\subsection{Repertory Grid Analysis for exploring brand positioning}

Kelly's (1955) repertory grid analysis (RGA) based on personal construct theory attempts to understand how individuals think about a given phenomenon in their world and construct their experience. RGA as cognitive mapping technique uncovers the personal constructs used by an individual to structure and interpret different events and objects in various contexts ranging from sociology to information technology (Tan and Hunter, 2002). In order to extract brand knowledge and identify brand position, RGA can be used to help people group objects and attributes according to their similarity and difference (Heine, 2009).

A repertory grid consists of three parts (Chang and Mak, 2018): 1) elements (e.g. brand name), 2) constructs (e.g. brand attributes), and 3) linking of elements on constructs (e.g. customer evaluation for each brand attribute for each brand name). Different from traditional questionnaire survey, RGA does not obtain answers from pre-defined questions but elicit respondent knowledge on selected topic (Denicolo et al., 2016). It provides a way to explore customer open-ended knowledge constructs without prejudging the terms of reference (Edwards et al., 2009; Hunter and Beck, 2000; McQualter, 1986).

In an interview of RGA, respondents are typically asked to select two elements they considered as similar on certain constructs and then provide another element different from these constructs. These differences are used to define the polar opposites of the emergent constructs. This procedure is repeated multiple times to identify important dimensions until no further new constructs are elicited. Finally, respondents are asked to rate elements on each of these detected constructs using a Likert scaling. The data set derived from the interview are inputted into a cross-table to present the ratings of elements on constructs. This matrix enables researchers to evaluate the relationship and connection strength between elements and construct dimensions by using dimensionality reduction analysis, such as principal component analysis (e.g., Hankinson, 2005; Plumeyer et al., 2017). 
In psychological and marketing researches, RGA has been widely used for exploring brand competitive landscape and validated in number of fields (e.g., Aaker, 1997; Caldwell and Coshall, 2002; Chang and Mak, 2018; Embacher and Buttle, 1989; GABOR, 2016; Hankinson, 2005; Heine, 2009; Kačániová and Szabová, 2014). For instance, Heine (2009) used RGA to uncover and compare luxury brand personality on five equity dimensions. Kačániová and Szabová (2014) examined customer perceptions of 8 web sites on 21 bipolar constructs for understanding web preferences of young people. By using repertory grid and principal component analysis, GABOR (2016) investigated the perceptions of Romanian customers on 20 car brands. Caldwell and Coshall (2002) examined the important concepts of visitors on 11 London museums. Aaker (1997) investigated customer perceptions of 37 well-known brands on 114 personality traits in various product categories and developed a well-known framework for exploring brand personality in five dimensions. In tourism, some empirical studies also employed RGA to figure out how tourists construed destinations and the destination images (e.g., Chang and Mak, 2018; Embacher and Buttle, 1989; Hankinson, 2005).

Plumeyer et al. (2017) performed a meta-analysis and stated that although there are several techniques for measuring brand image, most techniques are designed to assess brands in a non-competitive setting and repertory grid was recommended to map the image of more than one brand in a competitive environment. In this paper, we propose to employ RGA to uncover hotel brand positioning and competitive landscape by using UGC. RGA is originally designed for survey data, such as questionnaire or interview and therefore the biggest challenge is how to extract structured information from unstructured UGC to match the criterion of RGA. Hybrid approach of integrating content analysis and repertory grid analysis is developed to address this issue and further uncover competitive landscape involving both customer preferences and perceptions.

\section{Methodology}

\subsection{Research design}

Figure 1 shows the conceptual framework of our research approach guided by three key research issues: detecting brand performance, mapping competitive landscape and developing competitive strategies. The framework goes through three stages starting with data collection, followed by performing content analysis and lastly using repertory grid analysis (Figure 1). In the first stage, a crawling program was coded to collect hotel UGC from TripAdvisor.com resulting in collection of large size data for further analysis. In the second stage, the detected 
brand associations were manually filtered and coded as attributes. After this, Jaccard similarity coefficient and binomial proportion test were employed to evaluate the importance and performance of these coded attributes for selected hotel brands addressing first research issue of measuring brand performance.

In the last stages, the names of hotel brands, detected attributes and their importance value are input into a RGA program (Idiogrid) for uncovering brand positioning and competitive landscape. The use of principal component analysis at this stage helps us to answer research issue concerning mapping competitive landscape. To this end, first of all competitive groups were identified by setting a reference brand. RGA was performed again by employing related performance of brand attributes to answer the third research issue of developing competitive strategies.

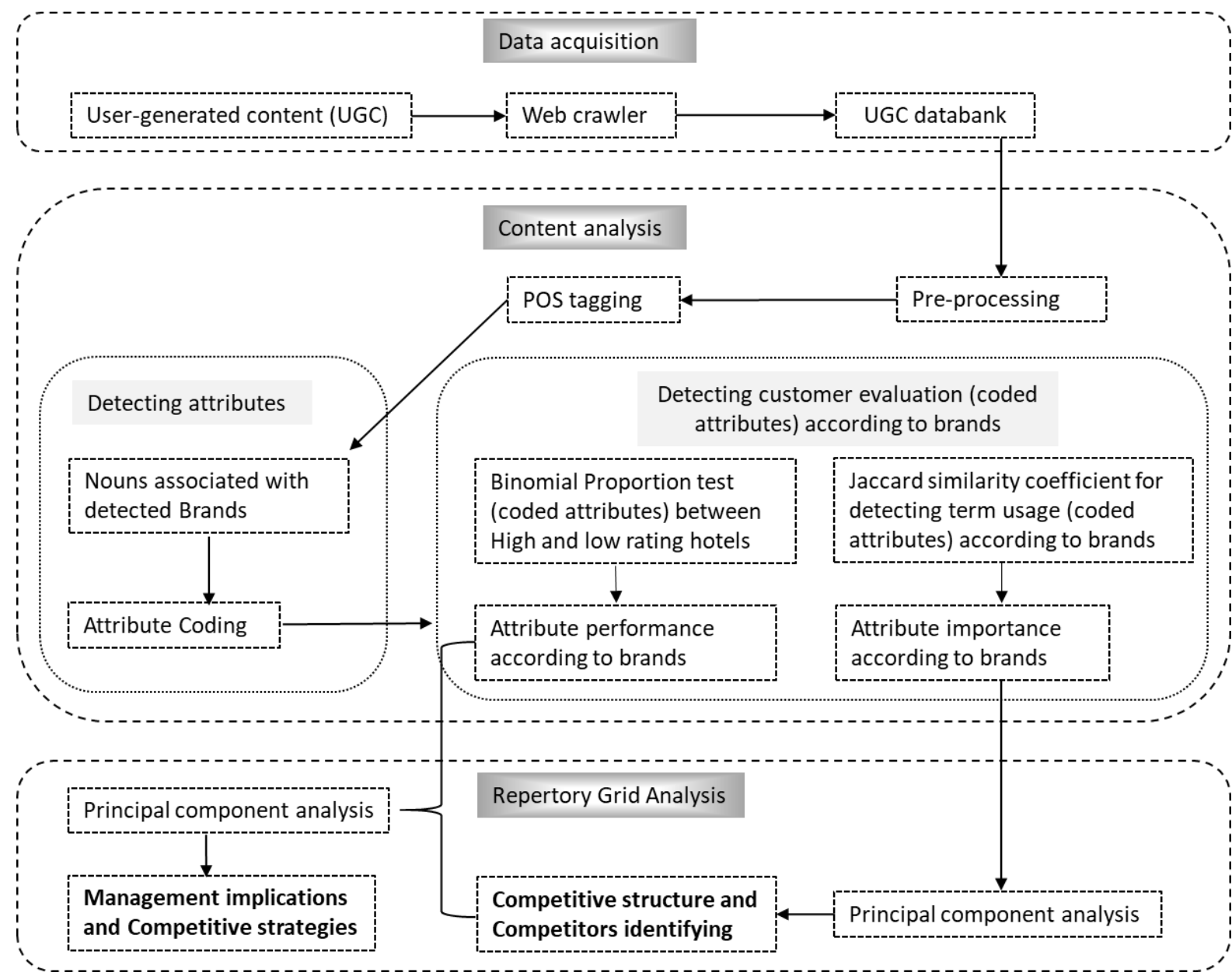

Figure 1: Research framework of uncovering brand competitive landscape by mining UGC

In previous studies, RGA was used for eliciting personal constructs based on survey data (e.g. Hankinson, 2005). In the current research study, RGA is employed to explore UGC with the help of text mining. Repertory grid interview mainly involves three parts: element selection, construct elicitation and element assessment (Chang and Mak, 2018; Jankowicz, 2005). Instead 
of using interview or survey method, we collected customer reviews from online platform and performed a content analysis to explore the key brand associations from consumer perspective. The detected brand attributes are further analyzed with repertory grid analysis. As Figure 2 shows, we replaced traditional interviews used in RGA by customer reviews. Here, elements are corresponded with selected hotel brands and detected brand attributes indicates constructs. We have used the customer evaluations of both preferences (importance) as well as perceptual performance to present the elements ratings on constructs.

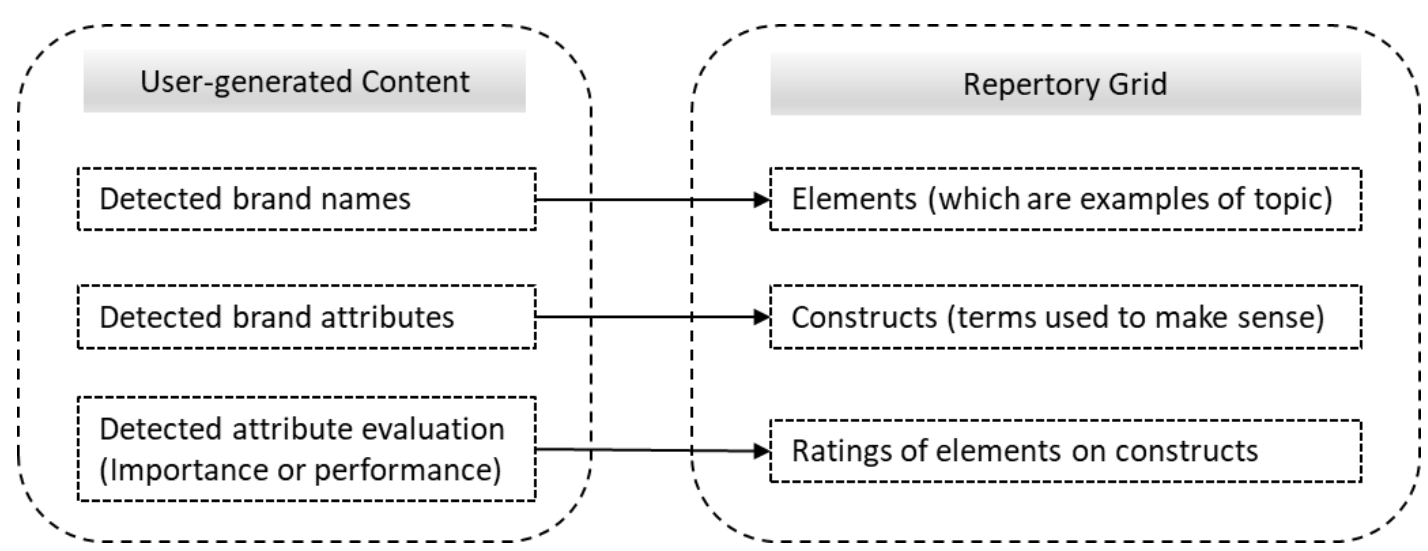

Figure 2: Repertory Grid analysis based on text mining UGC

\subsection{Data collecting}

Hotel reviews in TripAdvisor.com is a rich source of consumer opinion and contains valuable information like comments, overall rating, sub-rating, hotel types and hotel identification. A data collection program was used to crawl reviews about hotels in Beijing and Shanghai, China's two largest cities (and its most popular travel destinations) between May 22, 2004 and February 05, 2016. Software MySQL and textcat package in R (Hornik et al., 2013) were used to detect writing-language of each review. After filtering non-English data, 111,986 English reviews were used for further analysis. For each review, the review comment, overall rating, star rating and URL address were extracted. In the data preparation stage, the URL of each review was split into single word to identify hotel brand name and location. For instance, "http://*-Novotel_Xinqiao_Beijing-Beijing.html" indicates a "Novotel" hotel locating at Xinqiao, Beijing. As international tourists visiting China prefer to select higher quality international hotels, many international customers lodged in hotels with 3-5 stars. We therefore defined three major star categories: 3-3.5 stars hotels, 4-4.5 stars hotels and 5 stars hotels, and classified detected hotels into these categories. In this process, more than twenty international hotel brands were identified. Some hotel brands involved in more than one star-categories, such as Hilton and therefore they were excluded from our study. Only those brands ranked in only one of the star categories were kept for further analysis and two representative brands with 
highest number of consumer comments from each star-category were further selected as case sample to test our proposed model. As Table 2 shows, 6 international brands with total 13,147 customer reviews were used for further brand landscape analysis.

\begin{tabular}{lllll}
\hline Brand / Star & 3-3.5 stars & 4-4.5 stars & 5 stars & Total \\
\hline Holiday_Inn_Express & $1563(11.89 \%)$ & & & $1563(11.89 \%)$ \\
Ibis & $792(6.02 \%)$ & & & $792(6.02 \%)$ \\
Novotel & & $3034(23.08 \%)$ & & $3034(23.08 \%)$ \\
Crowne_Plaza & & $2868(21.81 \%)$ & & $2868(21.81 \%)$ \\
Shangri-La & & & $2915(22.17 \%)$ & $2915(22.17 \%)$ \\
Westin & & & $1975(15.02 \%)$ & $1975(15.02 \%)$ \\
\hline Total & $2355(17.91 \%)$ & $5902(44.89 \%)$ & $4890(37.19 \%)$ & $13147(100 \%)$ \\
\hline
\end{tabular}

Table 2. Distribution of customer reviews according to hotel brands

\subsection{Detecting Brand attributes}

Joyce (1963) argued that different methods of evaluating brand image could be broadly categorized into either sorting or scaling. The former mainly focuses on figuring out which attributes associates to a specific brand, while the latter emphasizes on evaluating the strength of associated attributes (Driesener and Romaniuk, 2006). In our research design, both sorting as well as scaling were integrated to visualize brand positioning based on text-mining UGC. Firstly, we identified key/unique brand attributes in online reviews based on association sorting. Following that, we assessed customer opinions on detected brand attributes by uncovering their importance (Ranking of Jaccard coefficient) and performance (Scaling of Z-scores). Finally, all those findings were transformed to scaling value for the purpose of visualization and developing competitive strategies.

In current research, $\mathrm{KH}-\mathrm{Coder}$, a quantitative textual analysis program was employed for brand attributes detection. In the pre-processing step, we transformed all letters in customer reviews into lowercase and stop words (such as "and", "is", "the") that provide no meaningful information were removed from the analysis. After executing a pre-processing analysis, a fourstep process was implemented to detect brand attributes. Firstly, nouns were set as part-ofspeech (POS) option for detecting brand associations. One commonly used technique for detecting product attributes is to use a POS tagger to annotate Nouns and Noun phrases in customer comments (e.g., Archak et al., 2011; Hu and Liu, 2004). In this study, we follow the technique adopted by $\mathrm{Hu}$ and Liu (2004) to use noun as POS to identify all the relevant brand attributes.

Secondly, we use the Jaccard coefficient to rank the importance/uniqueness of brand associations for each selected hotel brands. It has been argued in the past that simple frequency 
counting for selected key attributes may result into biased analysis (Hananto, 2015; Kudlats et al., 2014; Netzer et al., 2012) and therefore, previous studies have used different algorithms to detect associated attributes for distinct usages. For instance, in order to reduce the effect of document length on attribute detection, Hananto (2015) employed Term Frequency-Inverse Document Frequency (TF-IDF) to adjust the term weight. Netzer et al. (2012) used Lift ratio to detect attribute co-occurrence in brands with limited number of documents.

In order to detect unique brand associations (consumer preferences) for each selected hotel brand, the Jaccard coefficient is used to measure the attribute similarity between brands (Higuchi, 2016; Romesburg, 2004). Jaccard scores in this study are calculated at occurrence level. As following equation shows, our algorithm emphasize whether or not specific attribute occur regardless of whether the attribute appears once or multiple times in a document. In this way, the effect of document length is eliminated or reduced significantly.

$$
\begin{aligned}
& \text { Jaccard }=\frac{\mathrm{a}}{\mathrm{F} 1+\mathrm{F} 2-\mathrm{a}} \\
& \text { Where a is the frequency of documents including specified term in certain brand; } \\
& \text { F1 is the document frequency of this certain brand; } \\
& \text { F2 is the frequency of documents including the specified term in entire samples. }
\end{aligned}
$$

By using the Jaccard ranking, the unique attributes specific to each hotel brand can be easily identified. In the third step, we manually selected top 25 attributes with the highest Jaccard score for each of the six hotel brands separately. The last step is to create a combined attribute list based on above 150 detected words. By combining synonyms into terms, 30 terms were selected and coded as final attributes to input into KH-Coder for further analysis (Second column in Table 3 ).

\subsection{Evaluating Attribute Importance and Performance}

It has been widely recognized that satisfaction ratings given by customers reflect the performance of mentioned attributes (e.g., Albayrak and Caber, 2013; Mikulić and Prebežac, 2008), and proportion of mentioned attributes indicates the level of customer preference (e.g., Busacca and Padula, 2005; Stringam and Gerdes, 2010). A few previous hospitality studies employed difference between proportions method (DBPM) to compare the frequency of words in different usages (e.g., Lai and Hitchcock, 2017; Xiang et al., 2015; Xu and Li, 2016).

In this study, Jaccard coefficient and binomial proportion test are used to evaluate the difference of attribute importance and performance among brands. Jaccard ranking is used to indicate attribute preference (relative) instead of raw Jaccard coefficient (absolute) for reducing the 
effect of disproportionate sample distribution. We have tested two indicators (rank and score) and compared their outputs and found Jaccard ranking works better than raw Jaccard coefficient. For instance, airport (Jaccard: 0.070) is ranked as $1^{\text {st }}$ for Ibis, while bed (Jaccard: 0.071) is ranked as $8^{\text {th }}$ in Westin (See Table 3). Two attributes with almost equal Jaccard score get different ranking across selected reference hotels because of the disproportionate sample distribution (See Table 2). We argue that direct use of absolute raw Jaccard score would affect mapping of brand landscape by positioning attributes with similar Jaccard scores at same importance level. Furthermore, relative ranking matches well to traditional survey methods (such as Likert scale) in RGA. Jaccard ranking from small to large indicates customer preference towards hotel attributes from high to low.

Similarly, Z-score of binomial test is employed to indicate the attribute performance (relative). The following equation presents the formula employed in our study. In order to evaluate the performance of an attribute in a selected hotel brand, we compare the distribution of this attribute between high satisfaction category ( 5 rating) and low satisfaction (1-2 rating) category for selected hotel brands. Z-score with directions presents customer polar sentiment. In traditional statistical analysis, a critical value will be set to test predefined hypothesis. In current research, we employed original Z-sore to indicate customer perception towards attribute to match survey-based approach employed in RGA. Z-scores from large positive index to small negative index indicate customer perception towards hotel attributes from satisfied to dissatisfied.

$p^{1}:$ proportion of specified attribute in high rating category;

$p^{2}:$ proportion of specified attribute in low rating category;

The score test statistic is: $Z=\frac{\hat{p}_{1}-\hat{p}_{2}}{\sqrt{\hat{p}(1-\hat{p})\left(1 / n_{1}+1 / n_{2}\right)}}$

$\widehat{p}_{1}=x / n_{1}$ ( $x$ is the document frequency including specified attribute in high rating category; ${ }^{n_{1}}$ is the document number of this category);

$\hat{p}_{2}=y / n_{2}$ ( $y$ is the document frequency including specified attribute in low rating category, $n_{2}$ is the document number of this category);

$\hat{p}=(x+y) /\left(n_{1}+n_{2}\right)$ (where ${ }^{\hat{p}}$ is the estimate proportion of the specified attribute);

\subsection{Uncovering competitive landscapes and developing competitive strategies}

The last stage is about mapping competitive landscape and developing competitive strategies. Perceptual importance matrix is inputted into Idiogrid, a software originally designed around Kelly's (1955) repertory grid theory for uncovering competitive landscape. In this process, brand names are set as elements and attribute names are set as constructs, while importance 
value of attribute is set as rating. After conducting a principal component analysis, competitive landscape of hotel brands are visualized in multi-dimension graphs.

In this study, Euclidean distances between brands are selected as indicators for identifying key competitors. These indicators are not calculated on the basis of crude grid scores for each brand but factor scores of the detected principal components obtained from construct PCA. The distances are normalized using Slater's (1976) methods. The equation used to calculate normalized Euclidean distance between brands (Ugazio and Castiglioni, 1998) is presented as follows:

$$
\begin{aligned}
& d(a, b)=\frac{\sqrt{\left(a_{1}-b_{1}\right)^{2}+\ldots+\left(a_{k}-b_{k}\right)^{2}}}{\sqrt{2 n k /(n-1)}} \\
& \text { where } d \text { is the indicator of distance between brand a and } b ; \\
& \text { where } n \text { is the number of brands and } k \text { is the number of principal components; } \\
& \text { where } a_{k} \text { or } b_{k} \text { indicates the factor scores of brand a or } b \text { for } k_{t h} \text { components. }
\end{aligned}
$$

This index is taken as an indicator to detect similarity between reference element and other elements in multiple dimensions (e.g., Bender et al., 2009; Ugazio and Castiglioni, 1998). The lower the Euclidean distance between the elements, the greater the degree of identification and vice versa (Mackay, 1992). The mean of Euclidean distances between the reference brand and other brands is adopted as an index to identify key competitors (e.g., Bender et al., 2009; Ugazio and Castiglioni, 1998). Similar to this process, we further repeat principal component analysis by inputting attribute performance matrix for key competitive groups. The performances of attributes among competing brands are evaluated and compared for developing competitive strategies.

\section{Results and discussion}

\subsection{Customer evaluations to detected attributes}

Table 3 lists the importance level of top 30 attributes for 6 selected international hotel brands: Holiday Inn Express, Ibis, Novotel, Crowne Plaza, Shangri-La and Westin. The weight of attribute importance is ranked based on Jaccard coefficient according to brands. This table presents a unidimensional brand positioning and shows an obvious difference of customer preferences among 6 brands. For instance, looking at Shangri-La, we can see that attributes related to service, room and view appear more frequently in customer reviews. Crowne is referred for attributes related to room, staff and food. While customers are more concerned 
about airport, value and transport for Ibis and focus on transport, room as well as food for Holiday.

\begin{tabular}{|c|c|c|c|c|c|c|c|c|c|c|c|c|c|}
\hline $\mathbf{N}$ & Attributes & Ibis & Rank & Holiday & Rank & Novotel & Rank & Crowne & Rank & Westin & Rank & Shangri-La & Rank \\
\hline 1 & airport & 0.070 & 1 & 0.053 & 10 & 0.049 & 15 & 0.066 & 8 & 0.031 & 22 & 0.031 & 21 \\
\hline 2 & amenity & 0.004 & 27 & 0.012 & 25 & 0.032 & 19 & 0.052 & 14 & 0.070 & 9 & 0.064 & 11 \\
\hline 3 & bar & 0.020 & 20 & 0.030 & 18 & 0.031 & 20 & 0.047 & 19 & 0.041 & 15 & 0.050 & 14 \\
\hline 4 & bathroom & 0.031 & 10 & 0.041 & 13 & 0.041 & 18 & 0.050 & 16 & 0.057 & 10 & 0.045 & 17 \\
\hline 5 & bed & 0.040 & 8 & 0.056 & 9 & 0.068 & 10 & 0.058 & 12 & 0.071 & 8 & 0.041 & 18 \\
\hline 6 & club & 0.007 & 26 & 0.004 & 28 & 0.015 & 27 & 0.053 & 13 & 0.025 & 26 & 0.065 & 9 \\
\hline 7 & drink & 0.018 & 21 & 0.035 & 15 & 0.045 & 16 & 0.051 & 15 & 0.045 & 13 & 0.060 & 12 \\
\hline 8 & executive & 0.000 & 30 & 0.000 & 30 & 0.030 & 22 & 0.013 & 27 & 0.037 & 20 & 0.011 & 29 \\
\hline 9 & experience & 0.015 & 24 & 0.018 & 23 & 0.028 & 23 & 0.034 & 22 & 0.041 & 14 & 0.065 & 10 \\
\hline 10 & facility & 0.010 & 25 & 0.029 & 20 & 0.021 & 25 & 0.027 & 23 & 0.027 & 23 & 0.035 & 20 \\
\hline 11 & floor & 0.023 & 18 & 0.030 & 19 & 0.076 & 9 & 0.049 & 17 & 0.053 & 11 & 0.072 & 7 \\
\hline 12 & food & 0.031 & 11 & 0.103 & 3 & 0.138 & 3 & 0.133 & 3 & 0.107 & 3 & 0.122 & 5 \\
\hline 13 & lobby & 0.017 & 22 & 0.027 & 21 & 0.061 & 11 & 0.074 & 6 & 0.072 & 7 & 0.080 & 6 \\
\hline 14 & location & 0.048 & 6 & 0.074 & 6 & 0.139 & 2 & 0.094 & 5 & 0.076 & 6 & 0.072 & 8 \\
\hline 15 & luxury & 0.003 & 29 & 0.004 & 29 & 0.003 & 30 & 0.004 & 30 & 0.009 & 30 & 0.023 & 23 \\
\hline 16 & reception & 0.050 & 5 & 0.061 & 8 & 0.061 & 11 & 0.049 & 18 & 0.039 & 17 & 0.040 & 19 \\
\hline 17 & room & 0.054 & 4 & 0.104 & 2 & 0.170 & 1 & 0.161 & 1 & 0.118 & 2 & 0.145 & 3 \\
\hline 18 & service & 0.026 & 16 & 0.036 & 14 & 0.080 & 8 & 0.097 & 4 & 0.106 & 4 & 0.155 & 1 \\
\hline 19 & shopping & 0.029 & 13 & 0.044 & 11 & 0.086 & 7 & 0.065 & 9 & 0.037 & 19 & 0.059 & 13 \\
\hline 20 & staff & 0.035 & 9 & 0.071 & 7 & 0.118 & 5 & 0.135 & 2 & 0.097 & 5 & 0.128 & 4 \\
\hline 21 & suite & 0.003 & 28 & 0.006 & 27 & 0.018 & 26 & 0.016 & 25 & 0.035 & 21 & 0.014 & 27 \\
\hline 22 & toilet & 0.020 & 19 & 0.015 & 24 & 0.012 & 28 & 0.011 & 28 & 0.014 & 28 & 0.012 & 28 \\
\hline 23 & tour & 0.016 & 23 & 0.044 & 11 & 0.055 & 13 & 0.042 & 20 & 0.038 & 18 & 0.028 & 22 \\
\hline 24 & towel & 0.029 & 14 & 0.007 & 26 & 0.007 & 29 & 0.008 & 29 & 0.009 & 29 & 0.008 & 30 \\
\hline 25 & transport & 0.055 & 3 & 0.124 & 1 & 0.131 & 4 & 0.070 & 7 & 0.047 & 12 & 0.046 & 15 \\
\hline 26 & value & 0.061 & 2 & 0.086 & 4 & 0.090 & 6 & 0.059 & 10 & 0.040 & 16 & 0.046 & 16 \\
\hline 27 & view & 0.026 & 15 & 0.031 & 17 & 0.042 & 17 & 0.036 & 21 & 0.120 & 1 & 0.152 & 2 \\
\hline 28 & water & 0.023 & 17 & 0.034 & 16 & 0.031 & 21 & 0.023 & 24 & 0.025 & 25 & 0.020 & 25 \\
\hline 29 & wifi & 0.041 & 7 & 0.075 & 5 & 0.051 & 14 & 0.059 & 10 & 0.027 & 24 & 0.022 & 24 \\
\hline 30 & window & 0.030 & 12 & 0.019 & 22 & 0.026 & 24 & 0.015 & 26 & 0.016 & 27 & 0.016 & 26 \\
\hline
\end{tabular}

Table 3. Attribute preference according to hotel brands: Jaccard Score and Ranking

Similarly, table 4 presents the performance level of top 30 associated attributes according to brands. Here, relative ranking is also presented based on Z-score of binomial proportion test. For instance, Shangri-La is appreciated for food, view and location, while Westin is admired for view, shopping and amenity. Holiday and Novotel both perform well on value, transport and shopping. Similar to table 3 , table 4 provides a unidimensional score of brand performance. Further, the results from table 3 and 4 are used as input of Idiogird (principal component analysis) for exploring richer implications mapping brand competitive landscape (section 4.2) and developing competitive strategies (section 4.3).

\begin{tabular}{lllllllllllllll}
\hline $\mathbf{N}$ & Attributes & Ibis & Rank & Holiday & Rank & Novotel & Rank & Crowne & Rank & Westin & Rank & Shangri-La & Rank \\
\hline $\mathbf{1}$ & airport & 1.866 & 9 & 4.747 & 6 & 2.472 & 11 & -1.373 & 25 & 2.851 & 11 & 0.882 & 23 \\
$\mathbf{2}$ & amenity & 0.635 & 11 & 2.379 & 13 & 3.756 & 9 & 5.528 & 4 & 4.352 & 4 & 4.042 & 3 \\
$\mathbf{3}$ & bar & 0.383 & 12 & 2.194 & 15 & 1.174 & 16 & -0.877 & 23 & 2.793 & 12 & 0.469 & 24 \\
$\mathbf{4}$ & bathroom & -0.988 & 22 & 0.131 & 24 & -2.380 & 27 & 1.171 & 17 & 2.902 & 10 & 1.657 & 17 \\
$\mathbf{5}$ & bed & -1.298 & 26 & 2.067 & 17 & 1.070 & 18 & 3.165 & 9 & 3.630 & 6 & 2.072 & 13 \\
$\mathbf{6}$ & club & -0.257 & 17 & 0.336 & 23 & 0.204 & 22 & 2.854 & 10 & 2.585 & 13 & 3.006 & 7 \\
$\mathbf{7}$ & drink & 0.091 & 13 & 0.530 & 22 & 3.635 & 10 & 0.593 & 21 & 0.951 & 21 & -0.710 & 28
\end{tabular}




\begin{tabular}{|c|c|c|c|c|c|c|c|c|c|c|c|c|c|}
\hline 8 & executive & 0.000 & 14 & -1.143 & 27 & 1.105 & 17 & 1.249 & 16 & 3.035 & 8 & 1.263 & 21 \\
\hline 9 & experience & -1.109 & 24 & 0.571 & 21 & -4.903 & 29 & -1.901 & 28 & -2.205 & 29 & 2.025 & 14 \\
\hline 10 & facility & -0.723 & 21 & 2.810 & 10 & 1.948 & 12 & 3.731 & 7 & 1.788 & 18 & 1.115 & 22 \\
\hline 11 & floor & -1.175 & 25 & 2.432 & 12 & 0.590 & 21 & 1.328 & 15 & 1.397 & 19 & 2.456 & 12 \\
\hline 12 & food & 3.244 & 7 & 5.041 & 4 & 8.378 & 3 & 6.396 & 2 & 5.631 & 1 & 2.720 & 9 \\
\hline 13 & lobby & -2.068 & 28 & 2.555 & 11 & 1.521 & 15 & 1.064 & 18 & 2.939 & 9 & 2.965 & 8 \\
\hline 14 & location & 4.183 & 4 & 4.921 & 5 & 6.777 & 4 & 5.864 & 3 & 4.408 & 3 & 3.728 & 4 \\
\hline 15 & luxury & -0.416 & 19 & 2.321 & 14 & 0.875 & 19 & 1.885 & 12 & 2.192 & 16 & 1.624 & 18 \\
\hline 16 & reception & -1.534 & 27 & -1.771 & 30 & -4.949 & 30 & -3.035 & 30 & -4.829 & 30 & -0.069 & 26 \\
\hline 17 & room & -0.261 & 18 & 0.997 & 18 & -0.856 & 24 & -1.648 & 27 & 1.226 & 20 & 3.318 & 6 \\
\hline 18 & service & -1.044 & 23 & 0.668 & 20 & 0.768 & 20 & 1.869 & 13 & -0.617 & 27 & 3.331 & 5 \\
\hline 19 & shopping & 5.413 & 2 & 5.725 & 3 & 9.426 & 1 & 7.709 & 1 & 3.521 & 7 & 4.140 & 2 \\
\hline 20 & staff & 1.897 & 8 & 3.989 & 8 & 4.599 & 5 & 3.834 & 6 & -0.334 & 24 & 1.996 & 15 \\
\hline 21 & suite & 0.000 & 14 & 0.922 & 19 & 1.556 & 14 & 0.641 & 20 & 2.246 & 15 & 1.891 & 16 \\
\hline 22 & toilet & -2.357 & 29 & -0.569 & 26 & -1.530 & 25 & 0.680 & 19 & -0.357 & 26 & 0.136 & 25 \\
\hline 23 & tour & 3.338 & 6 & 3.331 & 9 & 3.827 & 8 & 3.720 & 8 & 2.332 & 14 & 2.488 & 11 \\
\hline 24 & towel & -2.394 & 30 & -0.065 & 25 & -2.034 & 26 & 1.529 & 14 & -0.200 & 23 & -0.336 & 27 \\
\hline 25 & transport & 5.310 & 3 & 7.260 & 1 & 8.806 & 2 & 4.477 & 5 & 4.270 & 5 & 2.522 & 10 \\
\hline 26 & value & 6.088 & 1 & 6.546 & 2 & 4.263 & 6 & -0.367 & 22 & 0.050 & 22 & -1.456 & 29 \\
\hline 27 & view & 3.612 & 5 & 2.164 & 16 & 4.069 & 7 & 2.281 & 11 & 5.621 & 2 & 5.682 & 1 \\
\hline 28 & water & -0.502 & 20 & -1.523 & 28 & -0.780 & 23 & -1.345 & 24 & -0.350 & 25 & -1.513 & 30 \\
\hline 29 & wifi & 1.219 & 10 & 4.013 & 7 & 1.741 & 13 & -1.472 & 26 & -0.636 & 28 & 1.539 & 19 \\
\hline 30 & window & -0.218 & 16 & -1.670 & 29 & -2.669 & 28 & -2.272 & 29 & 1.824 & 17 & 1.309 & 20 \\
\hline
\end{tabular}

Table 4. Attribute performance according to hotel brands: Z-score and Ranking

\subsection{Competitive landscape}

\subsubsection{Customers' preferences according to brands}

After deriving attribute importance coefficient (Jaccard score in table 3), we performed RGA to explore brand image and competitive landscape. A principal component analysis of the brand associations involving 6 selected brands on 30 attributes resulted in a 3-dimension solution with $87.20 \%$ cumulative variance explained. Table 5 presents the eigenvalues and explained variance of this 3-dimensional solution.

\begin{tabular}{lllll}
\hline PCs & Eigenvalue & \% Variance & Cumulative \% & Scree \\
\hline PC_1 & 12.93 & 43.10 & 43.10 & $* * * * * * * * * *$ \\
PC_2 & 7.77 & 25.91 & 69.01 & $* * * * * *$ \\
PC_3 & 5.46 & 18.19 & 87.20 & $* * * * *$ \\
\hline
\end{tabular}

Table 5. Principal component analysis of Brand associations

Table 6 summarizes the factor loading of selected thirty attributes for three dimensions. We further group these attributes into several categories according to their loading value. PC1 presents Advanced-offers (e.g. staff, lobby, food, service, drink, amenity, etc.) and Basic-offers (e.g. toilet, towel, window, reception, water, etc.). PC2 shows Experience (such as view, bar and experience) and Convenience (e.g. shopping, wifi and transport). While PC3 relates to Luxury (e.g. luxury and club) and Comfort (e.g. bed and executive).

\begin{tabular}{llllllllll}
\hline $\mathbf{N}$ & Attributes & PC_1 & PC_2 & PC_3 & N & Attributes & PC_1 & PC_2 & PC_3 \\
\hline $\mathbf{1}$ & airport & 0.72 & 0.57 & 0.04 & $\mathbf{1 6}$ & reception & 0.82 & 0.38 & 0.31
\end{tabular}




\begin{tabular}{llllllllll}
$\mathbf{2}$ & amenity & -0.79 & -0.56 & -0.12 & $\mathbf{1 7}$ & room & -0.79 & 0.45 & 0.39 \\
$\mathbf{3}$ & bar & -0.38 & -0.78 & -0.38 & $\mathbf{1 8}$ & service & -0.85 & -0.38 & -0.31 \\
$\mathbf{4}$ & bathroom & 0.65 & -0.53 & 0.42 & $\mathbf{1 9}$ & shopping & -0.15 & 0.95 & -0.15 \\
$\mathbf{5}$ & bed & 0.44 & 0.07 & 0.89 & $\mathbf{2 0}$ & staff & -0.9 & 0.06 & -0.22 \\
$\mathbf{6}$ & club & -0.42 & -0.09 & -0.82 & $\mathbf{2 1}$ & suite & -0.54 & -0.56 & 0.57 \\
$\mathbf{7}$ & drink & -0.81 & -0.36 & -0.24 & $\mathbf{2 2}$ & toilet & 0.99 & 0.1 & 0.02 \\
$\mathbf{8}$ & executive & -0.58 & -0.32 & 0.68 & $\mathbf{2 3}$ & tour & -0.25 & 0.45 & 0.49 \\
$\mathbf{9}$ & experience & -0.43 & -0.77 & -0.44 & $\mathbf{2 4}$ & towel & 0.97 & 0.04 & 0.07 \\
$\mathbf{1 0}$ & facility & -0.21 & -0.16 & -0.57 & $\mathbf{2 5}$ & transport & 0.51 & 0.73 & 0.41 \\
$\mathbf{1 1}$ & floor & -0.6 & -0.41 & -0.2 & $\mathbf{2 6}$ & value & 0.68 & 0.69 & 0.24 \\
$\mathbf{1 2}$ & food & -0.87 & 0.13 & 0.22 & $\mathbf{2 7}$ & view & -0.18 & -0.93 & -0.17 \\
$\mathbf{1 3}$ & lobby & -0.87 & -0.31 & -0.17 & $\mathbf{2 8}$ & water & 0.77 & 0.49 & 0.19 \\
$\mathbf{1 4}$ & location & -0.25 & 0.6 & 0.63 & $\mathbf{2 9}$ & wifi & 0.56 & 0.76 & 0.15 \\
$\mathbf{1 5}$ & luxury & -0.06 & -0.32 & -0.89 & $\mathbf{3 0}$ & window & 0.96 & 0.17 & 0.03 \\
\hline
\end{tabular}

Table 6. Structure Coefficients of brand attributes in 3-dimensions

Appendix A visualizes the relationships between each brand and selected 30 attributes (Absolute Structure Coefficients > 0.7), wherein A(1) presents the mapping of competitive landscape by PC1 \& PC2 and A(2) shows the same for PC1 \& PC3. Here, brand images and competitive landscapes can be clearly visualized and compared to identify key and distant competitors. For instance, Shangri-La is located at the bottom-left quadrant closely along with Westin on A(1). This indicates that customers perceives Shangri-La and Westin to be similar on PC1 \& PC2 and thus competing strongly against each other in most attributes. While $\mathrm{A}(2)$ shows completely different positioning of Shangri-La and Westin on PC3.

\subsubsection{Competitors identification in multiple dimensions}

In order to further determine the similarities and differences between selected brands, we compare these six brands at dimension level. As discussed in Section 3.5, we used the element loading to indicate Euclidean distance between brands in multiple dimensions. Table 7 shows the element loading of each brand and figure 3 visualizes the competitive landscape at dimension level. For instance, customers frequently mention experience and advanced-offers when lodging in Shangri-La and Westin. While Shangri-La is more close to luxury, Westin is mentioned more about comfort. Convenience and comfort are frequently associated with Ibis and Holiday. While customers mention more about basic-offers rather than advanced-offers when lodging in Ibis as compare to Holiday.

\begin{tabular}{llll}
\hline Brands & PC_1 & PC_2 & PC_3 \\
\hline Ibis & 2.92 & 1.18 & 0.7 \\
Holiday & 1.12 & 1.2 & 0.62 \\
Novotel & -0.36 & 0.98 & 0.93 \\
Crowne & -0.8 & 0.4 & -0.15 \\
Westin & -1.31 & -1.87 & 0.26 \\
Shangri-La & -1.57 & -1.88 & -2.35 \\
\hline
\end{tabular}




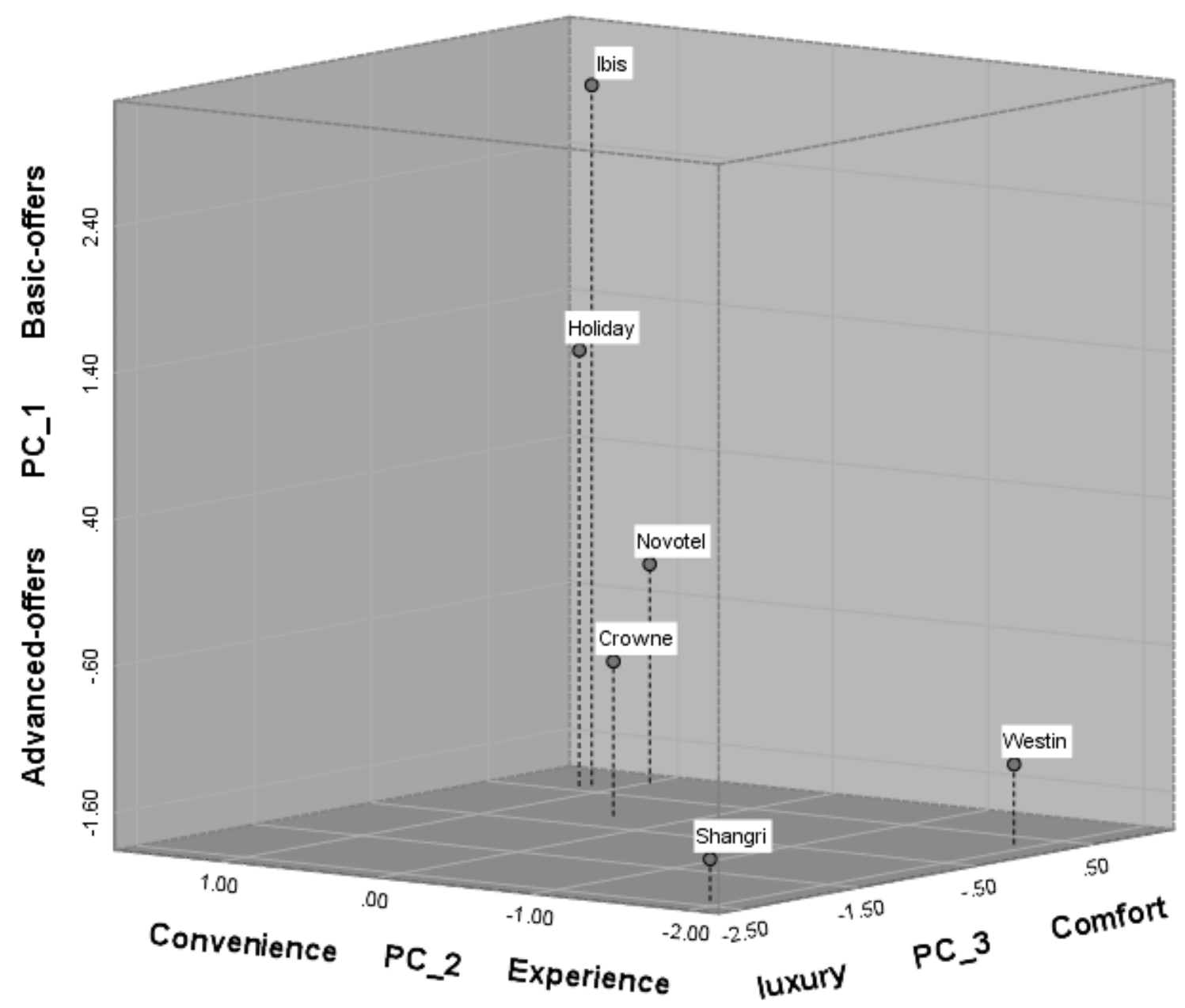

Figure 3. Competitive landscape of brands at dimension level

Table 8 shows the cross-value of Euclidean distances between selected six brands in 3 dimensional space. The mean value of Euclidean distances is employed as a reference to identify brand similarity. If a cross-value between two brands is smaller than the mean, we define them are competitors. For instance, the second row in table 8 presents the competitive conditions of Ibis brand. Referencing to the mean of this row (1.52), we identify that Holiday, Novotel and Crowne are the main competitors to Ibis.

\begin{tabular}{lllllll|l}
\hline & Ibis & Holiday & Novotel & Crowne & Westin & Shangri-La & Mean \\
\hline Ibis & 0.00 & 0.67 & 1.23 & 1.45 & 1.95 & 2.32 & 1.52 \\
Holiday & 0.67 & 0.00 & 0.57 & 0.83 & 1.47 & 1.88 & 1.08 \\
Novotel & 1.23 & 0.57 & 0.00 & 0.49 & 1.15 & 1.68 & 1.02 \\
Crowne & 1.45 & 0.83 & 0.49 & 0.00 & 0.88 & 1.22 & 0.97 \\
Westin & 1.95 & 1.47 & 1.15 & 0.88 & 0.00 & 0.98 & 1.28 \\
Shangri-La & 2.32 & 1.88 & 1.68 & 1.22 & 0.98 & 0.00 & 1.62 \\
\hline Mean & 1.52 & 1.08 & 1.02 & 0.97 & 1.28 & 1.62 & \\
\hline
\end{tabular}


In order to simplify the maps of brand landscape, we only included two main competitors for each reference brand in the following analysis. Table 9 presents the competitive landscape between 6 brands with only two key competitors for each reference brand. Here, we can see that there are main 3 competitive groups for 6 selected hotel brands corresponding with three hotel star categories: 3-3.5 stars, 4-4.5 stars and 5 stars. In the first group (3-3.5 stars), Ibis and Holiday are selected as references. Holiday and Novotel are reported as main competitors to Ibis, while Holiday compete with Novotel and Ibis. The second group (4-4.5 stars) involves Novotel and Crowne. Here, they compete strongly with each other as well as Holiday. The third group presents the competitive conditions of Westin and Shangri-La (5 stars). Westin and Crowne are reported as competitors to Shangri-La. When setting Westin as reference, Crowne and Shangri-La are found be key competitors.

\begin{tabular}{llll}
\hline Groups & Reference & Competitors (Ranking by Euclidean distance) \\
\hline Group 1 & Ibis & 1 Holiday & 2 Novotel \\
Group 1 & Holiday & 1 Novotel & 2 Ibis \\
Group 2 & Novotel & 1 Crowne & 2 Holiday \\
Group 2 & Crowne & 1 Novotel & 2 Holiday \\
Group 3 & Westin & 1 Crowne & 2 Shangri-La \\
Group 3 & Shangri-La & 1 Westin & 2 Crowne \\
\hline
\end{tabular}

Table 9. Competition between 6 hotel brands

\subsection{Improvement strategies according to competitions}

We performed RGA again to evaluate customer perceptions of brand performance in detected competitive groups (please see table 9). In Appendix B, figure 3 shows the attribute performance in group 3 (Shangri-La, Westin and Crowne). For instance, compare to the Westin, Shangri-La offers better executive and bar but need to improve experience and service. In order to obtain competitive position and create strong brand equity, Shangri-La should improve or maintain the performance of these attributes when competing with Westin. Especially, service is considered as core attribute for Shangri-La (see Table 3). Hotel resources therefore should be channelized towards managing and improving service. When selecting Westin as reference and comparing with Crowne, Appendix B (3) indicates that Westin performs better in room, service, club, etc. and but need to work on value, drink, food, etc. Appendix B (1) and (2) visualize the performance condition of Group 1 and Group 2 respectively. Our findings help to uncover the implications related to developing marketing strategy for all the selected brands to compete effectively. 


\section{Implications}

By mining 111,986 reviews, this paper examined customer preferences and perceptions towards six international hotel brands on thirty self-reported attributes. Thereafter, customer preferences (attribute importance) were employed to detect brand positioning as well as competitive groups. Further, customer perceptions (attribute performance) were used to suggest strategies for identified competitive groups. Our findings offers comprehensive implications for hotel brand positioning/re-positioning involving three key research issues: brand performance, competitive landscape and developing competitive strategies.

\subsection{Theoretical Implications}

Most of the existing literature on brand competitive landscape investigated customer evaluations from uni-dimensional perspective. For instance, Table 1 lists twenty hospitality studies related to brand competitive landscape. Here, twelve of them explored brand competition based on investigating perceptual importance, while the other nine were conducted based on examining perceptual performance. The main theoretical contribution of this study is to identify brand positioning and competitive landscape by employing both customer expectations and perceptions simultaneously in a single setting. This is in line with the ECT paradigm (Oliver, 1980). According to Oliver (1980) and Robets \& Lilien (1993), customers' evaluation of product/service should involve both expectations and perceptions. From the perspective of customers, brand performance is a reflection of confirmation between expectations and perceptions leading to customers' future behavior.

In this paper, we divide brand positioning and brand landscape mapping investigation into two stages. Firstly, customer expectations on attributes in terms of brands (importance) are employed to identify brand positioning and competitive groups. Thereafter, customer perceptions on attributes (performance) are used to indicate the performance of competitive brands to develop competitive strategies for identified competitive groups. This two-stage design can help researchers to comprehensively map brand positioning in a highly competitive environment answering all the three key underlying research issues derived in section 1 . In addition, the key problems of ECT involve measuring and scaling of expectations and perceptions (Pizam and Ellis, 2016). This study contributes to ECT literature by providing empirically validated solution to this problem by text-mining UGC.

The second theoretical contribution relates to the theory of competitive asymmetry. Against generally conceived notion, the level of competition between two brands may not be equal: Brand A may compete more intensely with brand B but the same may not hold true for 
Brand B (Desarbo et al., 2006). This research extends this asymmetry by not only identifying the key competitors but also uncovering the key attributes that forms the basis of asymmetric competition. From a theoretical standpoint, this study contributes in uncovering the mechanism and landscaping of competitive asymmetries based on text mining. For instance, as Figure 3 and Table 8 show, Westin is detected as the closest competitor to Shangri-La (Compete in experience and advanced offers), while the strongest competitor of Westin is Crowne (Compete in comfort and advanced offers). Similarly, Holiday is key competitor to Ibis (Compete in comfort and basic offers), while the main competitor of Holiday is Novotel (Compete in comfort). Furthermore, by detecting customer preferences alongside hotel stars, we discovered the inhomogeneous (asymmetric) market segments in hospitality industry. For instance, the key competitor is located in the same hotel star categories for most of the investigated hotel brands, such as Ibis, Novotel, Crowne and Shangri. While for remaining two brands, key competitor is found in different hotel star categories, e.g. Novotel (4-stars) to Holiday (3-stars) and Crowne (4-stars) to Westin (5-stars). Once market segments are identified, it is possible to make predictions about the groups' responses to various competitive strategies pursued by a key competitor, to align marketing strategies and to allow more creative and better-targeted response to dynamic external and competitive situations.

Thirdly, this paper tries to map brand competitive landscape with multi-dimensional insights. Previous studies of brand landscape often use a 2-dimensional visualization (e.g. corresponding analysis) that explains limited variance in data. Thus, it may misrepresent marketplace perceptions as positioning data are commonly considered multi-dimensional in nature (Whitlark and Smith, 2001). Our empirical findings validate that brands commonly position and compete using more than two dimensions. In this study, we adopted a method of identifying entity similarity in multi-dimensional space recommended by Slater (1976) and Ugazio \& Castiglioni (1998). In order to identify the difference between hotel brands, we employed factor scores to calculate the Euclidean distances between brands in all detected dimensions. We argue that this approach enables a researcher in capturing semantic multidimensionality reflecting the degree of differentiation used by customers in attributing constructs to the brand (Ugazio and Castiglioni, 1998). For instance, Shangri-La and Westin in our case show greater similarity on PC1 and PC2, while difference is detected only on PC3. Therefore, it is possible that important brand positioning implications between Shangri-La and Westin might be missed if employing a simple 2-dimensional analysis. Similar condition is also reported for Ibis and Holiday (please refer appendix A). 
Last but not least, this study is the first attempt using RGA to map brand positioning and competitive landscape by mining unstructured UGC. It is expected that the use of big-size UGC can uncover more precise and comprehensive understanding of brand positioning and competitive landscaping. As text mining is slowly replacing survey-based (e.g., questionnaire or interview) research techniques (Kozinets, 2002), this paper illustrates how text mining works on this issue with providing empirically enriched scientific insights (Chang et al., 2014). Traditionally, RGA was used to elicit personal constructs based on interviews, while we have used large scale widely available UGC to map brand positioning by employing the basic framework suggested by Kelly (1955). This allows us to use well-known RGA to map brand positioning and determine the brand landscape of selected reference hotel in relation to other players in the competitive group. However, this innovative approach of using RGA on unstructured data is not without limitations. Firstly, the process of RGA as used traditionally in interview involves concept eliciting and rating. We argue that the process of interviews is timeconsuming and cost-intensive (Plumeyer et al., 2017). In addition, only small size of interviewee can be investigated in RGA resulting into information selection bias. In this paper, RGA is conducted based on big size of UGC removing the limitations of interview-based techniques by automated content analysis. As figure 2 shows, the useful customer experience are extracted and evaluated in line with the process and criterion set in RGA. Our design therefor offers an advanced and automated approach for researchers planning to map brand landscape in a more objective manner.

\subsection{Practical Implications}

The large volume of UGC offers an unparalleled opportunity to practitioners working in the hospitality industry to analyze customer experiences more systematically and scientifically, leading to better insights as compare to traditional surveys (George et al., 2014; Krawczyk and Xiang, 2016). The insights drawn from the present study can help hoteliers to better understand their brand position in the selected market and improve their performance on core brand attributes against key competitors. Guided by our three key research questions, this study investigated customer expectations and perceptions towards six hotels located in China on thirty key attributes via text mining and repertory grid analysis.

The empirical results report the similarity and difference of customers' expectations towards different hotel brands from both attribute as well as dimension perspective. For instance, at the attribute level, service, lobby, drink, amenity, experience and view are marked by customers on Shangri-La and Westin. While customers mentioned more of luxury and club and 
less of room on Shangri-La than Westin. At dimension level, our findings also present comprehensive brand positioning of the selected hotels. Advanced-offers and experience are found to be closely related to higher-star hotels (e.g., Shangri-La and Westin). While Convenience, basic-offers and comfort are frequently discussed in lower-star hotels (e.g., Ibis and Holiday). Along with identifying key expectations separately in each of the six hotel brands (Figure 3), our findings present comprehensive and distinctive brand positioning for selected hotels from customer perspective.

To further map the competitive landscape, it is very important to find the key competitors and competitive dimensions as they are critical to a firm's success and achieving unique positioning (Brown and Ragsdale, 2002; Lewis, 1985). To this end, this paper firstly identified key competitors for all the six hotel brands and then presented critical competitive dimensions on which the reference brand competes with the competing groups. Our analysis identified three competitive groups from six selected hotel brands and uncovered asymmetric competitive relationship among them. For instance, in the first group, Holiday is found to be the main competitor of Ibis, while the key competitor for Holiday is Novotel. Similarly asymmetry is found in third group wherein Westin is the key competitor of Shangri-La, but Crowne fiercely competes with Westin. Along with identifying key competitors separately in each of the competing groups, our findings also presented the nuanced understanding behind this competition from attribute and dimension perspective.

The last and most important part is developing the strategy to outperform the competitors. Based on the detected competitive groups, we further compare the performance of a hotel brand on most relevant key attributes with other players in the same group to develop effective strategic recommendations. To this effect, as the resources available with any hotel brand is scarce and limited, it is necessary for any hotelier to prioritize the attributes that requires higher attention while competing with other key players in the market. For instance, Westin is identified as the key competitor for Shangri-La in this study and service is one of the important attribute for success of both the brands. Our findings shows that service is rated better in the case of Westin than Shangri-La, which indicates that Shangri-La should immediately focus on the improvement of attributes in service for effectively competing with Westin. Furthermore, in the case of Shangri-La, experience is considered more important and evaluated higher than Westin, which indicates that Shangri-La should keep on focusing here to maintain competitive superiority over Westin (Albayrak and Caber, 2015). 
In summary, our results provide unique insights for uncovering brand positioning and developing competitive landscaping from customer perspective (Appendix A and B). Overall, this study can help hoteliers at three levels, i.e. detecting brand performance, mapping competitive landscape and develop competitive strategies. By selecting a reference hotel brand, the hoteliers can better understand positioning of their brand in the mind of consumers and at the same time compete effectively by prioritizing their resource allocation on key attributes. Thus, our novel study help not only in strengthening positioning of a brand in the mind of customers but also compete in a cost-effective manner. We argue that the integrated approach introduced in the study can be replicated in other industries for mapping brand positioning and understanding competitive landscape based on text mining.

\section{Limitations and future research}

This paper has several limitations. In this study, 111,986 reviews in English language are used to analyze customer reviews for six hotel brands based in China. However, there may exist a cross-culture difference in customers' expectations and perceptions (Bodet et al., 2017; Dolnicar et al., 2007; Liu et al., 2017; Schuckert et al., 2015) limiting the findings of the study in uncovering tourist experience with different cultural backgrounds. Future studies may use the research methodology employed in this study to analyze UGC involving different languages, such as German, Chinese, Japanese, Russian, etc. Furthermore, although six international hotel brands with largest review frequency are selected in this study, these brands involve three different types of hotels (3-3.5 stars, 4-4.5 stars and 5 stars) with only two brands in each segments. This set-up was specifically designed to validate the proposed methodology. While brand positioning commonly focuses on key dimensions in a specific market, future researches could use more brands in each selected hotel-types for managerial insights. Future researchers can also use the month/year of review time in the analysis framework to map longitudinal change in the brand positioning of a selected hotel in relation to its key competitors. Furthermore, advanced content analysis methods such as Semantic Latent Indexing (Deerwester et al., 1990) and Aspect-based Sentiment Analysis (Hu and Liu, 2004), are expected to aid the detection of customers' brand evaluations in future research.

\section{References}

Aaker, J.L., 1997. Dimensions of Brand Personality. Journal of Marketing Research 34, 347. https://doi.org/10.2307/3151897

Albayrak, T., Caber, M., 2015. Prioritisation of the hotel attributes according to their influence on satisfaction: A comparison of two techniques. Tourism Management 46, 43-50. https://doi.org/10.1016/j.tourman.2014.06.009 
Albayrak, T., Caber, M., 2013. Penalty-Reward-Contrast Analysis: a review of its application in customer satisfaction research. Total Quality Management \& Business Excellence 24, 1288-1300. https://doi.org/10.1080/14783363.2013.776757

Anderson, R.I., Fish, M., Xia, Y., Michello, F., 1999. Measuring efficiency in the hotel industry: A stochastic frontier approach. International Journal of Hospitality Management 18, 45-57. https://doi.org/10.1016/S0278-4319(98)00046-2

Archak, N., Ghose, A., Ipeirotis, P.G., Ipeirotis., P.G., 2011. Deriving the Pricing Power of Product Features by Mining Consumer Reviews. Management Science 57, 1485-1509. https://doi.org/10.1287/mnsc.1110.1370

Bender, A., Jenkins, J.L., Scheiber, J., Sukuru, S.C.K., Glick, M., Davies, J.W., 2009. How Similar Are Similarity Searching Methods? A Principal Component Analysis of Molecular Descriptor Space. Journal of chemical information and modeling 49, 108-119. https://doi.org/10.1021/ci800249s

Bodet, G., Anaba, V., Bouchet, P., 2017. Hotel attributes and consumer satisfaction: A crosscountry and cross-hotel study. Journal of Travel \& Tourism Marketing 34, 52-69. https://doi.org/10.1080/10548408.2015.1130109

Brown, J.R., Ragsdale, C.T., 2002. The competitive market efficiency of hotel brands: An application of data envelopment analysis. Journal of Hospitality and Tourism Research 26, 332-360. https://doi.org/10.1177/109634802237483

Busacca, B., Padula, G., 2005. Understanding the relationship between attribute performance and overall satisfaction: Theory, measurement and implications. Marketing Intelligence \& Planning 23, 543-561. https://doi.org/10.1108/02634500510624110

Cai, L.A., Hobson, J.S.P., 2004. Making hotel brands work in a competitive environment. Journal of Vacation Marketing 10, 197-208. https://doi.org/10.1177/135676670401000301

Calantone, R.J., Di Benedetto, C.A., Hakam, A., Bojanic, D.C., 1989. Multiple multinational tourism positioning using correspondence analysis. Journal of Travel Research 28, 2532. https://doi.org/10.1177/004728758902800207

Caldwell, N., Coshall, J., 2002. Measuring brand associations for museums and galleries using repertory grid analysis. Management Decision 40, 383-392. https://doi.org/10.1108/00251740210426376

Chang, R.C.Y., Mak, A.H.N., 2018. Understanding gastronomic image from tourists' perspective: A repertory grid approach. Tourism Management 68, 89-100. https://doi.org/10.1016/j.tourman.2018.03.004

Chang, R.M., Kauffman, R.J., Kwon, Y.O., 2014. Understanding the paradigm shift to computational social science in the presence of big data. Decision Support Systems 63, 67-80. https://doi.org/10.1016/j.dss.2013.08.008

Chen, J.S., Uysal, M., 2002. Market positioning analysis: A hybrid approach. Annals of Tourism Research 29, 987-1003. https://doi.org/10.1016/S0160-7383(02)00003-8

Chiu, C., Chiu, N.H., Sung, R.J., Hsieh, P.Y., 2015. Opinion mining of hotel customergenerated contents in Chinese weblogs. Current Issues in Tourism 18, 477-495. https://doi.org/10.1080/13683500.2013.841656 
Choi, T.Y., Chu, R., 2001. Determinants of hotel guests' satisfaction and repeat patronage in the Hong Kong hotel industry. International Journal of Hospitality Management 20, $277-$ 297. https://doi.org/10.1016/S0278-4319(01)00006-8

Crotts, J.C., Mason, P.R., Davis, B., 2009. Measuring guest satisfaction and competitive position in the hospitality and tourism industry: An application of stance-shift analysis to travel blog narratives. Journal of Travel Research 48, 139-151.

https://doi.org/10.1177/0047287508328795

Curry, B., Davies, F., Phillips, P., Evans, M., Moutinho, L., 2001. The Kohonen selforganizing map: an application to the study of strategic groups in the UK hotel industry. Expert systems 18, 19-31. https://doi.org/10.1111/1468-0394.00152

Deerwester, S., Dumais, S.T., Furnas, G.W., Landauer, T.K., Harshman, R., 1990. Indexing by latent semantic analysis. Journal of the American Society for Information Science 41, 391-407. https://doi.org/10.1002/(SICI)1097-4571(199009)41:63.0.CO;2-9

Denicolo, P., Long, T., Bradley-Cole, K., 2016. Constructivist Approaches and Research Methods: A Practical Guide to Exploring Personal Meanings. Sage.

DeSarbo, W.S., Grewal, R., Wind, J., 2006. Who competes with whom? A demand-based perspective for identifying and representing asymmetric competition. Strategic Management Journal 27, 101-129. https://doi.org/10.1002/smj.505

Dev, C.S., Morgan, M.S., Shoemaker, S., 1995. A positioning analysis of hotel brands: Based on travel-manager perceptions. Cornell Hotel and Restaurant Administration Quarterly 36, 48-55. https://doi.org/10.1177/001088049503600617

Dolnicar, S., Grün, B., Grun, B., 2007. Assessing analytical robustness in cross-cultural comparisons. International Journal of Culture, Tourism and Hospitality Research 1, 140160. https://doi.org/10.1108/17506180710751687

Driesener, C., Romaniuk, J., 2006. Comparing methods of brand image measurement. International Journal of Market Research 48, 681-698. https://doi.org/10.5539/ass.v10n19p1

Edwards, H.M., McDonald, S., Young, S.M., 2009. The repertory grid technique: Its place in empirical software engineering research. Information and Software Technology 51, 785 798. https://doi.org/10.1016/j.infsof.2008.08.008

Embacher, J., Buttle, F., 1989. A repertory grid analysis of Austria's image as a summer vacation destination. Journal of Travel Research 27, 7. https://doi.org/10.1177/004728758902700302

GABOR, M.R., 2016. Romanian Young Consumers Perception of Car Brands: A Personal Construct Theory Approach. Eurasian Journal of Business and Economics 9, 17-39. https://doi.org/10.17015/ejbe.2016.018.02

George, G., Haas, M.R., Pentland, A., 2014. From the editors: Big data and management. Academy of Management Journal 57, 321-326. https://doi.org/10.5465/amj.2014.4002

Hananto, A., 2015. Application of Text Mining to Extract Hotel Attributes and Construct Perceptual Map of Five Star Hotels from Online Review : Stoudy of Jakarta and Singapore Five-Star Hotels. Asean Marketing Journal VII, 58-80. https://doi.org/10.21002/amj.v7i2.5262 
Hankinson, G., 2005. Destination brand images: A business tourism perspective. Journal of Services Marketing 19, 24-32. https://doi.org/10.1108/08876040510579361

Heine, K., 2009. Using personal and online repertory grid methods for the development of a luxury brand personality. Electronic Journal of Business Research Methods 7, 25-38.

Higuchi, K., 2016. KH Coder 3 Reference Manual.

Hornik, K., Mair, P., Rauch, J., Geiger, W., Buchta, C., Feinerer, I., 2013. The textcat Package for n-Gram Based Text Categorization in R. Journal of Statistical Software 52, $1-17$.

$\mathrm{Hu}$, M., Liu, B., 2004. Mining and summarizing customer reviews, in: Proceedings of the Tenth ACM SIGKDD International Conference on Knowledge Discovery and Data Mining. ACM, pp. 168-177. https://doi.org/10.1145/1014052.1014073

Hunter, M.G., Beck, J.E., 2000. Using Reperatory Grids to Conduct Cross-Cultural Information Systems Research. Information Systems Research 11, 93-101. https://doi.org/10.1287/isre.11.1.93.11786

Jankowicz, D., 2005. The easy guide to repertory grids. John wiley \& sons.

Joyce, T., 1963. Techniques of brand image measurement. New developments in research 1, 45-63.

Kačániová, M., Szabová, E., 2014. Perception of International Web Pages: a Repertory Grid Approach. Studia Ekonomiczne 205, 59-71.

Keller, K.L., 1993. Conceptualizing, Measuring, and Managing Customer-Based Brand Equity. Journal of Marketing 57, 1-22. https://doi.org/10.1177/002224299305700101

Kelly, G., 1955. Personal construct psychology. Nueva York: Norton.

Kim, D.J., Kim, W.G., Han, J.S., 2007. A perceptual mapping of online travel agencies and preference attributes. Tourism Management 28, 591-603. https://doi.org/10.1016/j.tourman.2006.04.022

Kim, H., 1998. Perceived attractiveness of Korean destinations. Annals of tourism research 25, 340-361. https://doi.org/10.1016/s0160-7383(98)00007-3

Kim, H., 1996. Perceptual mapping of attributes and preferences: an empirical examination of hotel F\&B products in Korea. International Journal of Hospitality Management 15, 373391. https://doi.org/10.1016/S0278-4319(96)00040-0

Kim, S.S., Agrusa, J., 2005. The positioning of overseas honeymoon destinations. Annals of tourism research 32, 887-904. https://doi.org/10.1016/j.annals.2004.12.004

Kim, S.S., Chun, H., Petrick, J.F., 2005a. Positioning analysis of overseas golf tour destinations by Korean golf tourists. Tourism Management 26, 905-917. https://doi.org/10.1016/j.tourman.2004.04.005

Kim, S.S., Guo, Y., Agrusa, J., 2005b. Preference and positioning analyses of overseas destinations by mainland Chinese outbound pleasure tourists. Journal of travel research 44, 212-220. https://doi.org/10.1177/0047287505278979

Kozak, M., 2004. Measuring comparative performance of vacation destinations: using 
tourists' self-reported judgements as an alternative approach. Consumer psychology of tourism, hospitality and leisure 3, 285-302.

Kozak, M., 2002. Comparative analysis of tourist motivations by nationality and destinations. Tourism Management 23, 221-232. https://doi.org/10.1016/S0261-5177(01)00090-5

Kozinets, R. V., 2002. The Field Behind the Screen: Using Netnography for Marketing Research in Online Communities. Journal of Marketing Research 39, 61-72. https://doi.org/10.1509/jmkr.39.1.61.18935

Krawczyk, M., Xiang, Z., 2016. Perceptual mapping of hotel brands using online reviews: a text analytics approach. Information Technology and Tourism 16, 23-43. https://doi.org/10.1007/s40558-015-0033-0

Kudlats, J., Money, A., Hair, J.F., 2014. Correspondence analysis: A promising technique to interpret qualitative data in family business research. Journal of Family Business Strategy 5, 30-40. https://doi.org/10.1016/j.jfbs.2014.01.005

Lai, I.K.W., Hitchcock, M., 2017. Sources of satisfaction with luxury hotels for new, repeat, and frequent travelers: A PLS impact-asymmetry analysis. Tourism Management 60, 107-129. https://doi.org/10.1016/j.tourman.2016.11.011

Lau, K.-N., Lee, K.-H., Ho, Y., 2005. Text Mining for the Hotel Industry. Cornell Hotel and Restaurant Administration Quarterly 46, 344-362. https://doi.org/10.1177/0010880405275966

Lewis, R.C., 1990. Advertising Your Hotel's Position. Cornell Hotel and Restaurant Administration Quarterly 31, 84-91. https://doi.org/10.1177/001088049003100213

Lewis, R.C., 1985. The market position: Mapping guests' perceptions of hotel operations. Cornell hotel and restaurant administration quarterly 26, 86-99. https://doi.org/10.1177/001088048502600222

Lewis, R.C., 1981. The positioning statement for hotels. Cornell Hotel and Restaurant Administration Quarterly 22, 51-61. https://doi.org/10.1177/001088048102200111

Liu, Y., Teichert, T., Rossi, M., Li, H., Hu, F., 2017. Big data for big insights: Investigating language-specific drivers of hotel satisfaction with 412,784 user-generated reviews. Tourism Management 59, 554-563. https://doi.org/10.1016/j.tourman.2016.08.012

Mackay, N., 1992. Identification, reflection, and correlation: Problems in the bases of repertory grid measures. International Journal of Personal Construct Psychology 5, 57 75. https://doi.org/10.1080/08936039208404941

Mazanec, J.A., 1995. Positioning analysis with self-organizing maps: an exploratory study on luxury hotels. Cornell Hotel and Restaurant Administration Quarterly 36, 80-95. https://doi.org/10.1016/0010-8804(96)81007-X

McQualter, J.W., 1986. Becoming a mathematics teacher: The use of personal construct theory. Educational Studies in Mathematics 17, 1-14.

Mikulić, J., Prebežac, D., 2008. Prioritizing improvement of service attributes using impact range-performance analysis and impact-asymmetry analysis. Managing Service Quality 18, 559-576. https://doi.org/10.1108/09604520810920068 
Netzer, O., Feldman, R., Goldenberg, J., Fresko, M., 2012. Mine Your Own Business: Market Structure Surveillance Through Text Mining. Marketing Science 31, 521-543. https://doi.org/10.1287/mksc.1120.0713

Oh, H., Parks, S.C., 1997. Customer satisfaction and service quality: A critical review of the literature and research implications for the hospitality industry. Hospitality Research Journal 20, 35-64. https://doi.org/10.1177/109634809602000303

Oliver, R.L., 1980. A Cognitive Model of the Antecedents and Consequences of Satisfaction Decisions. Journal of Marketing Research 17, 460-469. https://doi.org/10.1177/002224378001700405

Opoku, R.A., 2009. Mapping destination personality in cyberspace: An evaluation of country web sites using correspondence analysis. ournal of Internet Commerce 8, 70-87. https://doi.org/10.1080/15332860903182438

Park, C.W., Jaworski, B.J., Maclnnis, D.J., 1986. Strategic Brand Concept-Image Management. Journal of Marketing 50, 135-145. https://doi.org/10.2307/1251291

Pizam, A., Ellis, T., 2016. Customer satisfaction and its measurement in hospitality enterprises. International Journal of Contemporary Hospitality Management 28, 2-35. https://doi.org/10.1108/09596119910293231

Plumeyer, A., Kottemann, P., Böger, D., Decker, R., 2017. Measuring brand image: a systematic review, practical guidance, and future research directions. Review of Managerial Science 1-39. https://doi.org/10.1007/s11846-017-0251-2

Prasad, K., Dev, C.S., 2000. Managing Hotel Brand Equity. Cornell Hotel and Restaurant Administration Quarterly 41, 22-31. https://doi.org/10.1177/001088040004100314

Robets, J.H., Lilien, G.L., 1993. Explanatory and predictive models of consumer behavior. Handbooks in Operations Research and Management Science 27-82. https://doi.org/10.1016/S0927-0507(05)80025-8

Romesburg, C., 2004. Cluster analysis for researchers. Lulu.com.

Schuckert, M., Liu, X., Law, R., 2015. A segmentation of online reviews by language groups: How English and non-English speakers rate hotels differently. International Journal of Hospitality Management 48, 143-149. https://doi.org/10.1016/j.ijhm.2014.12.007

Slater, P.E., 1976. The measurement of intrapersonal space by grid technique. Vol. I. Explorations of Intrapersonal Space. London: Wiley.

Stringam, B.B., Gerdes, J., 2010. An Analysis of Word-of-Mouse Ratings and Guest Comments of Online Hotel Distribution Sites. Journal of Hospitality Marketing \& Management 19, 773-796. https://doi.org/10.1080/19368623.2010.508009

Tan, F.B., Hunter, M.G., 2002. The repertory grid technique: A method for the study of cognition in information systems. MIS Quarterly 39-57. https://doi.org/10.2307/4132340

Torres, E.N., Kline, S., 2006. From satisfaction to delight: A model for the hotel industry. International Journal of Contemporary Hospitality Management 18, 290-301. https://doi.org/10.1108/09596110610665302

Trout, J., Ries, A., 1972. Positioning cuts through chaos in marketplace. Advertising Age 43, 
$51-54$.

Ugazio, V., Castiglioni, M., 1998. Socialization models and the construction of self. Journal of Constructivist Psychology 11, 3-29. https://doi.org/10.1080/10720539808404636

Wen, C.-H., Yeh, W.-Y., 2010. Positioning of international air passenger carriers using multidimensional scaling and correspondence analysis. Transportation Journal 7-23.

Whitlark, D.B., Smith, S.M., 2001. Using Correspondence Analysis to Map Relationships. Marketing Research 13, 22-27.

Xiang, Z., Schwartz, Z., Gerdes, J.H., Uysal, M., 2015. What can big data and text analytics tell us about hotel guest experience and satisfaction? International Journal of Hospitality Management 44, 120-130. https://doi.org/10.1016/j.ijhm.2014.10.013

$\mathrm{Xu}, \mathrm{X} ., \mathrm{Li}, \mathrm{Y} ., 2016$. The antecedents of customer satisfaction and dissatisfaction toward various types of hotels: A text mining approach. International Journal of Hospitality Management 55, 57-69. https://doi.org/10.1016/j.ijhm.2016.03.003

Yamanishi, K., Li, H., 2002. Mining Open Answers in Questionnaire Data. IEEE Intelligent Systems 17, 58-63. https://doi.org/10.1109/MIS.2002.1039833

\section{Appendix}

\section{Appendix A. Competitive landscape of 6 hotel brands on 30 attributes}

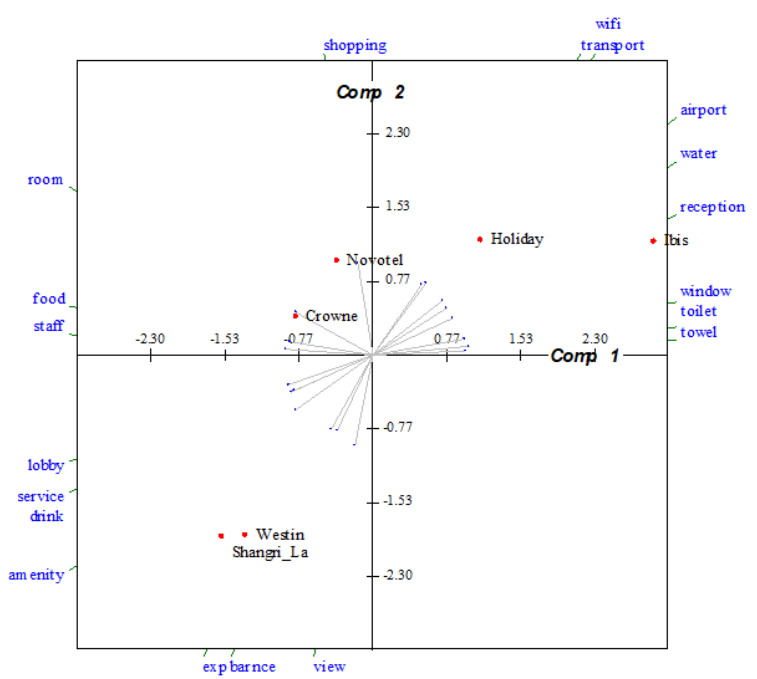

(1) PC1 \& PC2

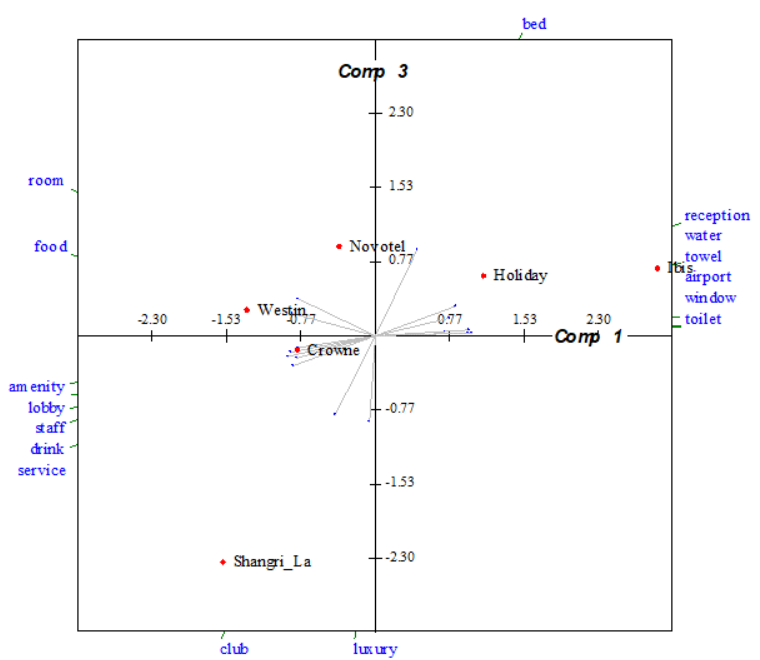

(2) PC1 \& PC3 
Appendix B. Improvement implications for 6 selected Brands
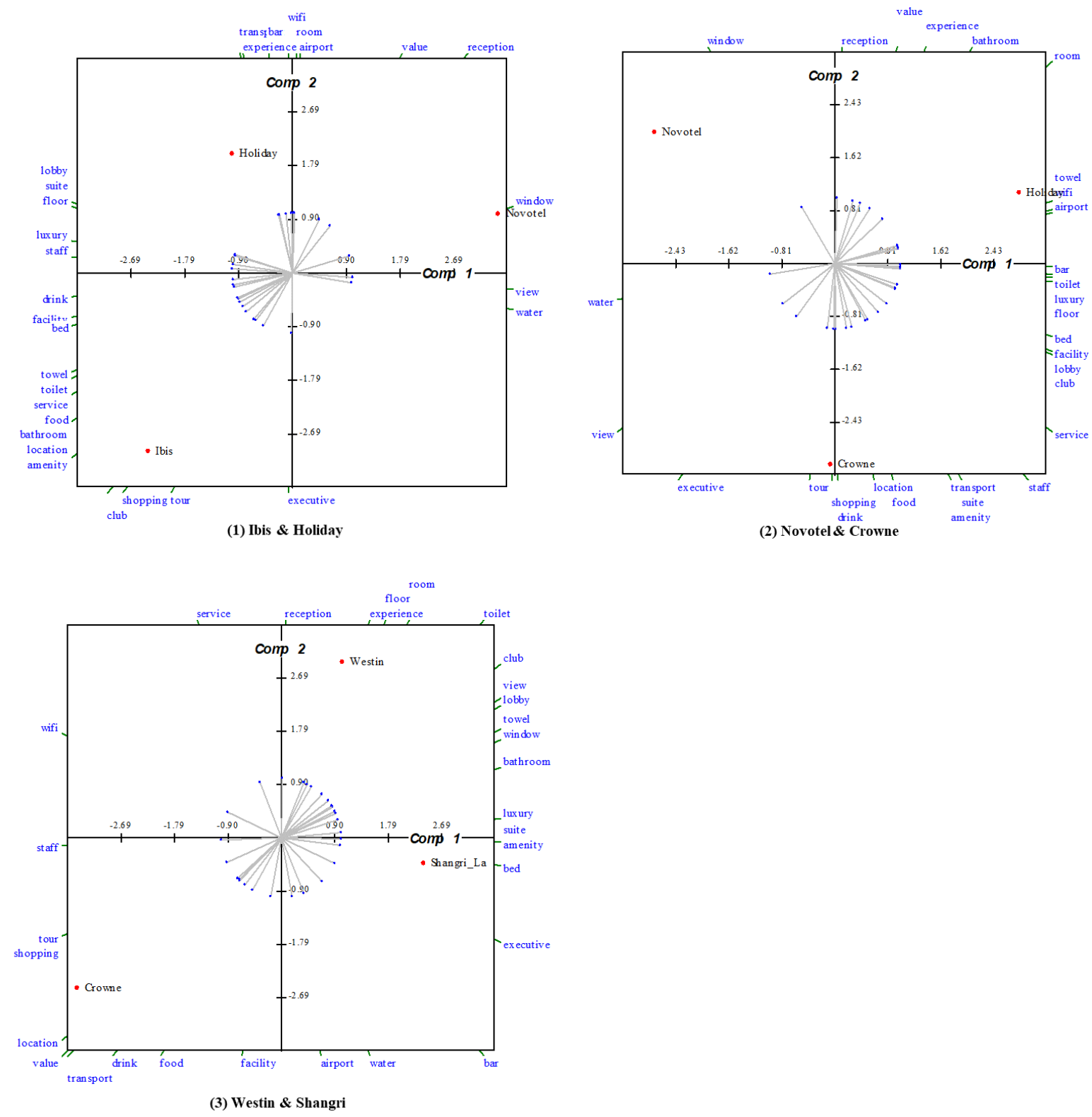